\title{
A New Synthetic Ursolic Acid Derivative IUA with Anti-Tumor Efficacy Against Osteosarcoma Cells via Inhibition of JNK Signaling Pathway
}

\author{
Jian Chen ${ }^{\mathrm{a}}$ Haijian Fu ${ }^{\mathrm{b}}$ Zhuoying Wang ${ }^{\mathrm{a}}$ Fei Yin ${ }^{\mathrm{a}}$ Jianxin Li $^{\mathrm{b}}$ Yingqi Hua \\ Zhengdong Cai ${ }^{\mathrm{a}}$
}

aDepartment of Orthopaedics, Shanghai First People's Hospital, Nanjing Medical University, Shanghai, bState Key Lab of Analytical Chemistry for Life Science, School of Chemistry and Chemical Engineering, Nanjing University, Nanjing, China

\section{Key Words}

Synthetic ursolic acid derivative $\cdot$ Osteosarcoma $•$ JNK

\begin{abstract}
Background: Osteosarcoma is the most common primary malignant bone tumor in children and adolescents and is characterized by frequent metastasis and resistance to chemotherapy. Because osteosarcoma cells are not highly susceptible to current chemotherapy drugs, new alternative strategies for the treatment of osteosarcoma are needed. This study was undertaken to investigate the inhibitory effects of a new synthetic ursolic acid derivative IUA on osteosarcoma cells and to explore its molecular mechanism. We also intended to identify new therapeutic candidates. Methods: We used MTT assay to assess the effect of IUA on the proliferation of osteosarcoma cells. Western-blot analysis was performed to examine downstream molecular events. The Annexin $V$ method was used to evaluate the effect of IUA on apoptosis of osteosarcoma cells. The cell cycle of IUA-treated cells was examined by flow cytometry, and the in vivo effects of this new ursolic acid derivative were evaluated in a mouse osteosarcoma model. Results: The results showed that the new synthetic ursolic acid derivative IUA significantly decreased viability of osteosarcoma cells in vitro and in vivo. It could also induce apoptosis and G1 phase arrest of osteosarcoma cells. The JNK signaling pathway was significantly inhibited, and cleaved caspase-3 protein was increased. Conclusion: We concluded that the new synthetic ursolic acid derivative IUA induces proliferation inhibition and apoptosis of osteosarcoma cells in vitro and in vivo via the down-regulation of the JNK signaling pathway, making it a promising agent for the prevention and treatment of human osteosarcoma.
\end{abstract}

Copyright $\odot 2014$ S. Karger AG, Basel

Yingqi Hua

and Zhengdong Cai
Shanghai Bone Tumor Institute, 200080, (China)

and Department of Orthopaedics, Shanghai First People's Hospital, Nanjing Medical

University, 6th Floor, Building 2, No. 100 Haining Road, Shanghai, 200080 (China)

E-Mail hua_yingqi@163.com and E-Mail caizhengdong1961@gmail.com 


\section{Introduction}

Osteosarcoma is the most common primary malignant bone tumor that occurs in children and adolescents [1]. It comprises about $20 \%$ of all primary bone cancers and is characterized by frequent metastasis and resistance to chemotherapy. Before the use of effective chemotherapy, the outcome for patients with osteosarcoma was poor, with 2 -year overall survival rates of $15 \%-20 \%$ following surgical resection or radiotherapy [2]. With the use of neoadjuvant chemotherapy in recent years, the long-term survival rate has been improved to $70 \%-80 \%$. However, the prognosis is still unsatisfactory because of lung metastasis or chemotherapy resistance. The most common chemotherapy agents are cisplatin, doxorubicin, and high-dose methotrexate [3]. Osteosarcoma cells are not highly susceptible to these drugs, and the serious side effects of chemotherapy are usually hard for patients to tolerate. Therefore, development of new alternative strategies for the treatment of osteosarcoma is necessary.

Ursolic acid (UA) is a natural pentacyclic triterpenoid carboxylic acid extracted from medical herbs and edible plants, and studies have shown that it unleashes a wide range of biological activities, including antiviral [4], anti-bacterial [5], hepatoprotective and antiinflammatory [6]. Furthermore, it has been involved in prevention and protection against cancers [7]. Its anti-tumor action is attributed to its ability to prevent tumorigenesis, inhibit proliferation, and induce apoptosis [8, 9]. The signaling pathways involved in UA activity might be different in various cancer cell lines, and the precise molecular mechanisms of UA involved in proliferation inhibition and apoptosis induction were still not clear. Since the biological activity of UA has been found to be relatively weak, we developed a new synthetic UA derivative: (1S,2R,4aS,6aS,6bR,13aR)-N-(1-benzylpiperidin-4-yl)-1,2,6a,6b,9,9,13aheptamethyl-1,2,3,4,4a,5,6,6a,6b,7,8,8a,9,13,13a,13b,14,15b-octadecahydropiceno[2,3-d] isoxazole-4a-carboxamide and its abbreviation is Isoxazole Usolic Amide 1a ( IUA ), which has a putatively much stronger biological activity compared to UA.

$\mathrm{C}$-Jun- $\mathrm{N}$-terminal kinase (JNK) is a mitogen-activated protein kinase family member that was first described in the early 1990s [10-12]. JNK is known to be involved in diverse cellular functions such as cell proliferation, differentiation, and apoptosis based on phosphorylation [13]. The role of the JNK pathway in apoptosis is still highly controversial. Activation of the JNK signaling pathway has now been frequently associated with apoptotic cell death, and inhibition of JNK can prevent apoptosis and death of multiple cells [14-16]. In some cell lines the converse has been reported: inhibition of JNK activity promoted apoptosis, and JNK activation protected cells from apoptosis [17-19]. Therefore, the role of JNK in cells' proliferation, apoptosis, and death is perplexing. JNK can work as positive or negative mediators in apoptosis, which could be accounted for by the possibility that multiple isoforms of JNK proteins exert different and opposite effects, and that phosphorylation by JNKs can lead to both activation and inhibition of substrate function [20].

Here, we evaluated the effect of IUA on osteosarcoma cells proliferation and apoptosis and analyzed its regulation of the key proteins in some signaling pathways involved in cell proliferation and apoptosis. Our results showed that anti-proliferation and pro-apoptotic effects of IUA in osteosarcoma cells were mediated through modulation of the JNK signaling pathway.

\section{Materials and Methods}

\section{Reagents and Antibodies}

IUA was synthesized by the School of Chemistry and Chemical Engineering, Nanjing University, China. ${ }^{a}$ Reagents and coditions: (a) 1-benzylpiperidin-4-amine, Et3N, rt, $\mathrm{CH} 2 \mathrm{Cl} 2,24 \mathrm{~h}$ (65\%). Figure 1 shows the outline for the synthesis of the compound IUA from compound 2. Compound 2 was synthesized following the reported method [21]. Then, to a stirred solution of 2 (96.68. $0.20 \mathrm{mmol})$ in anhydrous $\mathrm{CH} 2 \mathrm{Cl} 2(25 \mathrm{~mL})$ 
Fig. 1. Synthesis of new synthetic ursolic acid derivative, Isoxazole Usolic Amide. 1a (IUA) used in the study.

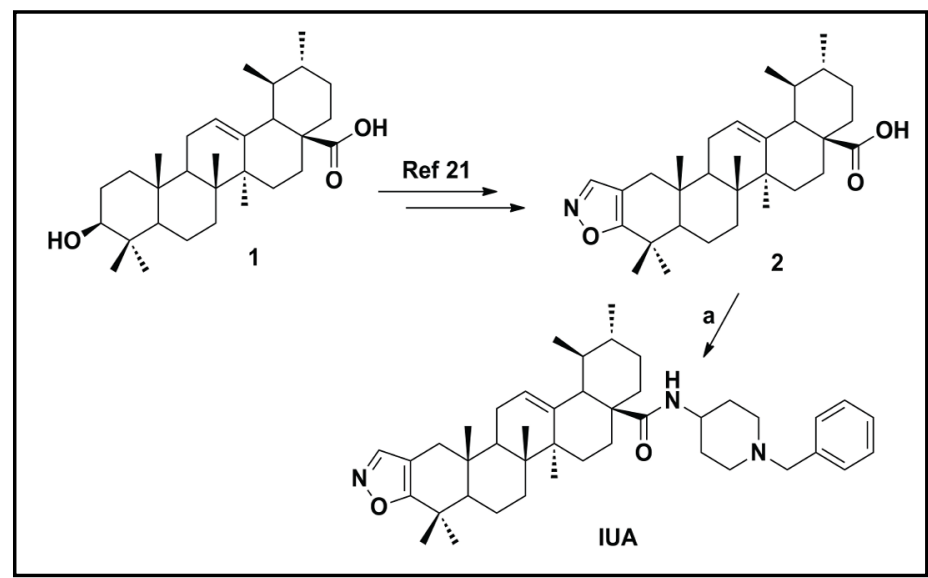

was added oxalyl chloride $(251.86 \mathrm{mg}, 2.0 \mathrm{mmol})$ at $0{ }^{\circ} \mathrm{C}$ and the reaction mixture was stirred overnight at room temperature. Then the solvent was removed and was added 1-benzylpiperidin-4-amine (0.24 mmol), Et3N (101.19 mg, $0.30 \mathrm{mmol}$ ) and stirred for $12 \mathrm{~h}$ at room temperature. On completion, the solvent was evaporated and the residue was poured into water $(50 \mathrm{~mL})$ and extracted with AcOEt $(50 \mathrm{~mL} \times 3)$. The organic layer was dried over anhydrous $\mathrm{Na} 2 \mathrm{SO} 4$ and evaporated. Then the crude compounds were purified by a column chromatography (PE/EA, 4/1, v/v) to afford 5 as white solid. Yield 65\%. White solid, mp 233$235^{\circ} \mathrm{C}$. $1 \mathrm{H}$ NMR $(300 \mathrm{MHz}, \mathrm{CDCl} 3) \delta: 7.98(\mathrm{~s}, 1 \mathrm{H}), 7.31(\mathrm{~s}, 1 \mathrm{H}), 7.27-7.21(\mathrm{~m}, 2 \mathrm{H}), 5.67(\mathrm{~d}, \mathrm{~J}=7.5 \mathrm{~Hz}, 1 \mathrm{H})$, $5.31(\mathrm{~s}, 1 \mathrm{H}), 3.82-3.71(\mathrm{~m}, 1 \mathrm{H}), 3.49(\mathrm{~s}, 2 \mathrm{H}), 2.84-2.74(\mathrm{~m}, 2 \mathrm{H}), 2.45(\mathrm{~d}, \mathrm{~J}=15.1 \mathrm{~Hz}, 1 \mathrm{H}), 2.17-1.96(\mathrm{~m}, 6 \mathrm{H})$, 1.94-1.66 (m, 8H), 1.51-1.39 (m, 7H), $1.30(\mathrm{~s}, 3 \mathrm{H}), 1.20(\mathrm{~s}, 3 \mathrm{H}), 1.11(\mathrm{~s}, 3 \mathrm{H}), 0.95(\mathrm{~s}, 3 \mathrm{H}), 0.89(\mathrm{~s}, 3 \mathrm{H}), 0.88$ $(\mathrm{d}, \mathrm{J}=5.9 \mathrm{~Hz}, 3 \mathrm{H}), 0.86(\mathrm{~d}, \mathrm{~J}=6.1 \mathrm{~Hz}, 3 \mathrm{H}) .13 \mathrm{C} \mathrm{NMR}(75 \mathrm{MHz}, \mathrm{CDCl} 3) \delta: 177.0,173.0,150.1,139.5,137.9$, 129.2, 128.2, 127.1, 125.2, 108.7, 63.1, 54.1, 53.4, 52.3, 52.2, 47.8, 46.2, 46.0, 42.7, 39.8, 39.6, 39.0, 38.6, 37.5, 35.6, 34.7, 32.2, 31.7, 30.9, 28.8, 27.9, 24.6, 23.4, 23.0, 21.3, 21.1, 18.7, 17.3, 17.1, 15.5. HR-MS (m/z) $[\mathrm{M}+\mathrm{H}]+(\mathrm{ESI}+)$ calcd for C43H62N3O2, 652.4837; found 652.4864. Stock solution at $20 \mathrm{mmol} / \mathrm{L}$ was made with dimethyl sulfoxide (DMSO; Sigma, America) and stored in the dark at $-20^{\circ} \mathrm{C}$. The final concentrations used for different experiments were prepared by diluting the stock solution with DMEM medium. Triazole nitrogen blue MTT (3-(4,5-dimethyl-2 thiazolyl)-2, 5-diphenyl tetrazolium bromide salt) and JNK inhibitor (sp600125) were purchased from Sigma Corporation. Rabbit monoclonal antibody against p-JNK, JNK, p-ERK, ERK, p-AKT, AKT, p-c-jun, c-jun, P65, caspase-3, caspase-9, PARP, and $\beta$-actin and goat or mouse antirabbit IgG were obtained from Cell Signaling (USA). Annexin V-FITC/PI and Hoechst 33342 were obtained from BD Biosciences (East Rutherford, NJ, USA).

\section{Cell lines and animals}

Human osteosarcoma cell lines U2-OS, HOS, and Saos- 2 were purchased from ATCC (USA). The mouse osteosarcoma cell line LM-8 was established by Tatsuya Asai, et al. Mouse cell lines K7, K7M3 were from Dr. Kleinerman's lab in MD Anderson Cancer Center, which were originally established by Khanna. All cells were cultured in DMEM media supplemented with 10\% heat-inactivated fetal bovine serum, $100 \mathrm{mg} /$ $\mathrm{ml}$ penicillin, and $100 \mathrm{mg} / \mathrm{ml}$ streptomycin. Cultures were maintained in an incubator with a humidified atmosphere of $95 \%$ air and $5 \% \mathrm{CO} 2$ at $37^{\circ} \mathrm{C}$. Mice were purchased from the Chinese Academy of Sciences (Shanghai, China).

\section{Cell proliferation analysis}

Osteosarcoma cells (U2-OS, HOS, Saos-2, K7, K7 M3 and LM-8) were seeded in a 96-well plate at 3-8×103 cells/well and cultured for 12 hours to allow attachment. Then cells were treated with a concentration gradient $(0,0.1,1,5$ and $10 \mu \mathrm{mol} / \mathrm{L})$ of IUA for different periods of time (0-72 hours), and afterwards 20 $\mu \mathrm{l}$ of MTT solution ( $5 \mathrm{mg} / \mathrm{ml}$, Sigma-Aldrich) was added into each well and incubated for $4 \mathrm{~h}$. The growth medium was then removed and replaced with DMSO $(150 \mu \mathrm{l} /$ well $)$ in order to solubilize the blue-purple crystals of formazan. The absorbance was then measured using a model ELX800 Micro Plate Reader (BioTec Instruments, Inc.) at $490 \mathrm{~nm}$. The survival rate = absorbance value of the treatment group / absorbance of the control group $\times 100 \%$. 
Flow cytometric analysis of apoptosis and cell cycle

Cells seeded in six-well plates at $2 \times 105$ cells/well and treated with IUA $(0,5,10 \mu \mathrm{mol} / \mathrm{L})$ for $48 \mathrm{~h}$ were trypsinized and harvested, then washed twice with phosphate-buffered saline. The cells used in cell cycle analysis were mixed in $300 \mu \mathrm{l}$ of $1 \times$ binding buffer, and incubated at room temperature for 15 min with propidium iodide (PI, Sigma , America), NP-40, and RNase A (BD Biosciences). The cells used in cell death analysis were mixed in $100 \mu \mathrm{l}$ of $1 \times$ binding buffer and incubated at room temperature for $15 \mathrm{~min}$ with an Annexin V/PI (BD Biosciences) double-staining solution. Stained cells were analyzed by flow cytometry. The percentage of cells in the different stages and the percentage of apoptosis cells were calculated using ModFit LT software (Verity Software House).

\section{Western-blot analysis}

K7, HOS and Saos-2 cells were treated with different concentrations of dex-UA for 8 hours . Cells were washed twice with PBS solution, lysed with RIPA Lysis Buffer (Beyotime Institune of Biote chnology, Shanghai, China) and protease inhibitor (Thermo scientific). Lysates were clarified by centrifugation at $12,000 \mathrm{rpm}$ for $10 \mathrm{~min}$ at $4^{\circ} \mathrm{C}$. Protein concentrations were determined by BCA protein assay kit (Thermo Scientific). Samples ( $50 \mu \mathrm{g}$ ) were boiled in an equal volume of sample buffer ( $20 \%$ glycerol, $4 \%$ SDS, $0.2 \%$ Bromophenol Blue, $125 \mathrm{mmol} / \mathrm{L}$ Tris-HCl (pH 7.5), and $640 \mathrm{mmol} / \mathrm{L} 2$-mercaptoethanol) and separated on 8-12\% SDS-polyacrylamide gels. Proteins resolved on the gels were transferred to nitrocellulose (NC) membranes. Membranes were blocked with $5 \%$ milk in $10 \mathrm{mmol} / \mathrm{L} \mathrm{Tris}-\mathrm{HCl}(\mathrm{pH} 8.0), 150 \mathrm{mmol} / \mathrm{L} \mathrm{NaCl}$ with $0.05 \%$ Tween-20 (TPBS) and probed with protein-specific antibodies to p-JNK, JNK, p-ERK, ERK, p-AKT, AKT, p-c-jun, c-jun, P65, caspase-3, caspase-9, PARP, or actin (all at 1:1000 dilution) overnight at $4^{\circ} \mathrm{C}$, washed for $10 \mathrm{~min}$ three times with Tween-20 (1:1000 dilution)-TPBS, followed by incubation with secondary antibodies (mouse anti-rabbit IgG) at room temperature for $1 \mathrm{~h}$. Membranes, washed for $10 \mathrm{~min}$ three times, and relative expression of proteins were analyzed using Odyssey software. The signal generated by Actin was used as an internal control.

\section{Xenograft model}

Four-week-old female BALB/c mice (weight 16-18 g) were kept under specific pathogen-free conditions and supplied with sterile food and water. Approximately $1 \times 10^{7} \mathrm{~K} 7$ cells were injected into the right femur of each nude mouse under aseptic conditions. Tumor growth was continuously monitored. When the size of the tumor reached $5 \mathrm{~mm} \times 5 \mathrm{~mm}$, mice were randomly divided into two groups $(\mathrm{n}=6)$, and IUA was intraperitoneally injected $(20 \mathrm{mg} / \mathrm{kg} / \mathrm{d})$ every other day. After two weeks, the mice were sacrificed, and the tumor legs were completely resected and weighed. The weight of the mice at the beginning and end of the experiment was also recorded. Percentage tumor inhibition was calculated as ( 1 - final weight of tumor in the experimental group / the final weight of tumor in the control group) $\times 100 \%$. This study was performed with the approval of the local ethical committee(NO 2014014) and all the experiments were performed according to the National Institutes of Health Guide for the Care and Use of Laboratory Animals.

\section{Statistical analysis}

Statistical analysis was performed using GraphPad Prism 5 (La Jolla, CA, USA). All measurement data were expressed as mean \pm standard deviation (SD) and compared between two groups using Student $t$ test. $P<0.05$ was considered statistically significant.

\section{Results}

\section{Effect of IUA on osteosarcoma cell proliferation}

To investigate the biological activity of our newly synthesized compound IUA on osteosarcoma cells, we measured its impact on the growth of a panel of osteosarcoma cells including K7, K7M3, LM8 HOS, U-2 OS, and Saos-2 by MTT assay. The results showed that IUA significantly decreased viability of osteosarcoma cells in a dose- and time-dependent manner. UA-derivative concentration of $10 \mu \mathrm{mol} / \mathrm{L}$ for 72 hours resulted in survival rates for K7, HOS, U2-OS, Saos-2, LM8, and K7M3 cells of $14.94 \pm 2.0,14.47 \pm 0.5,30.21 \pm 2.7,22.20 \pm 0.4$, $5.85 \pm 1.9$ and $20.10 \pm 0.3 \%$, with value of $P<0.05$ (Fig. 2). 


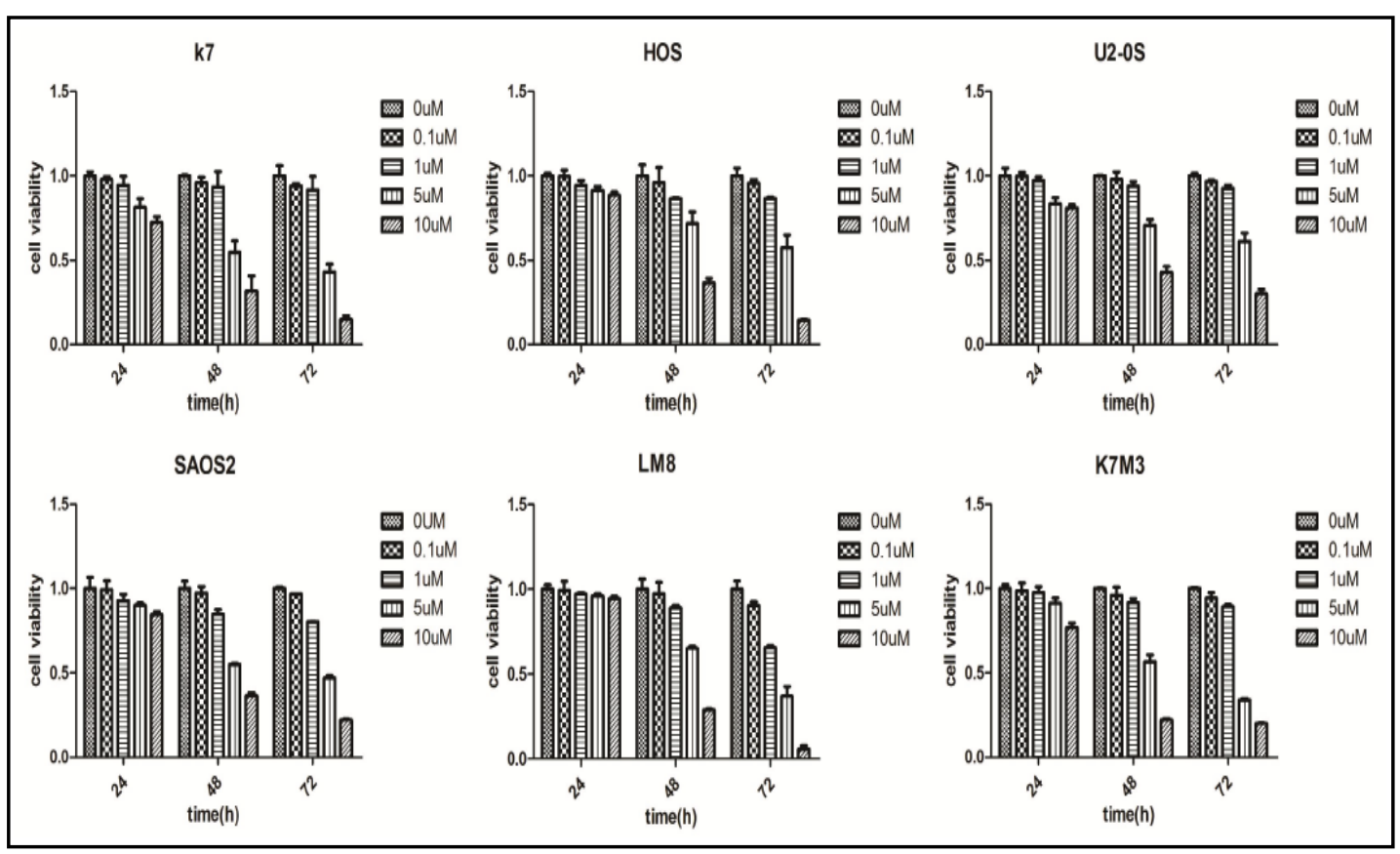

Fig. 2. Effects of IUA on sarcoma cell viability by MTT assay. K7, HOS, U2-OS, Saos-2, LM8, and K7M3 cells were cultured with different concentrations of IUA $(0,0.1,1,5$ and $10 \mu \mathrm{mol} / \mathrm{L})$ for 24,48 and $72 \mathrm{~h}$. The data were obtained from three independent experiments.

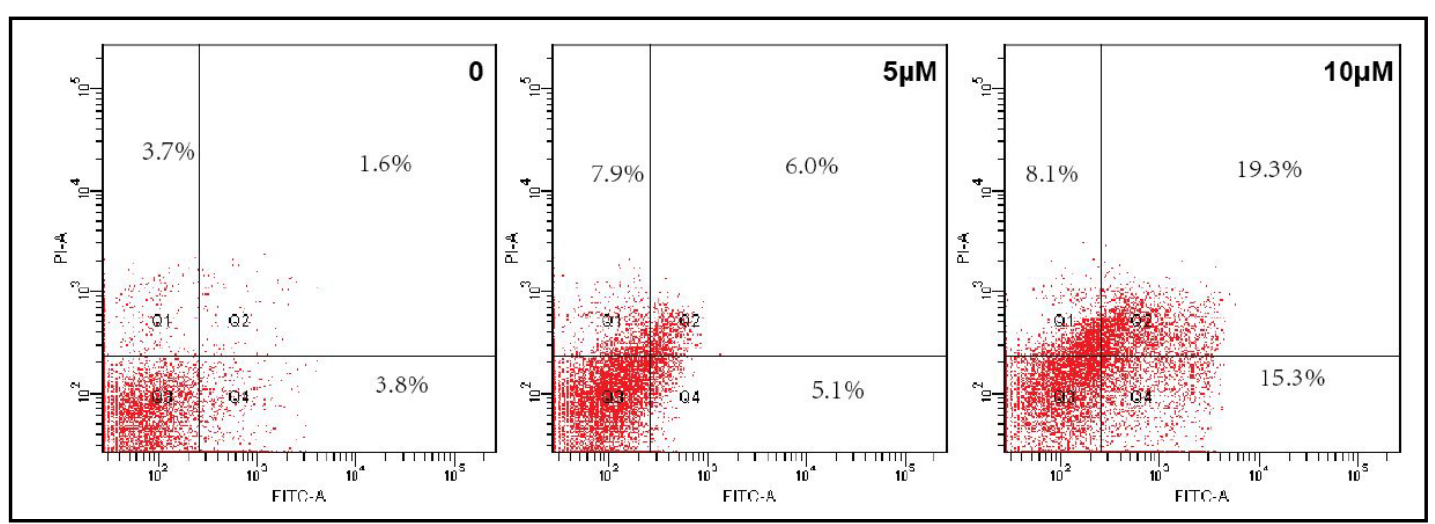

Fig. 3. IUA-induced apoptosis in osteosarcoma cells. Osteosarcoma cells K7 treated with IUA (0, 5, 10 $\mu \mathrm{mol} / \mathrm{L})$ after 48 hours.The percentage of early apoptotic and late apoptotic cells increased with the incubation time $(\mathrm{P}<0.05)$.

\section{IUA induces apoptosis of osteosarcoma cells}

Osteosarcoma cells K7 were treated with IUA (0, 5, $10 \mu \mathrm{mol} / \mathrm{L})$ for 48 hours. Annexin V/PI (BD Biosciences) double staining was conducted by flow cytometry. As shown in Fig. 3, the four quadrants in each panel correspond, respectively, to necrotic cells (upper left), late apoptotic cells (upper right), viable cells (lower left), and early apoptotic cells (lower right). Which showed that IUA induced early apoptosis and late apoptosis in the osteosarcoma cells (Fig. 3). At $5 \mu \mathrm{mol} / \mathrm{L}$, the apoptosis rate of $\mathrm{K} 7$ was $11.1 \%$, and at $10 \mu \mathrm{mol} / \mathrm{Lthe}$ apoptosis rate was $34.6 \%$. When compared with the rate in untreated control cells, which was $5.4 \%$, the result confirmed that IUA induces apoptosis of osteosarcoma cells.

IUA arrested osteosarcoma cells in G1 Phase

Mouse osteosarcoma cells K7 were treated for $48 \mathrm{~h}$ with IUA (0, 5, $10 \mu \mathrm{mol} / \mathrm{L})$. Using flow cytometry analysis, we showed that the $\mathrm{S}$ phase was significantly decreased and G1 


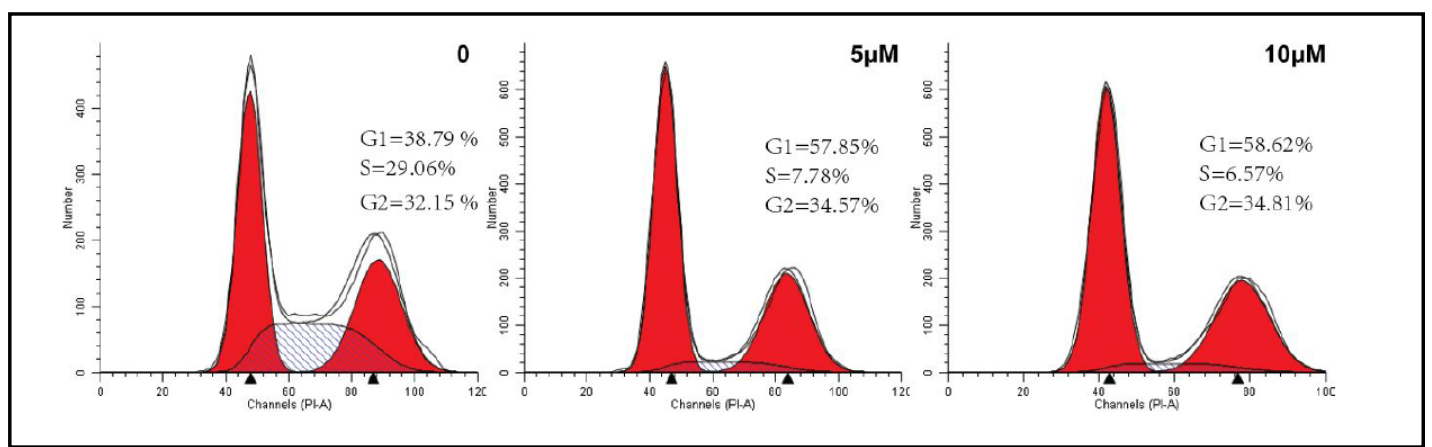

Fig. 4. Effect of IUA treatment on the cell cycle of osteosarcoma cells. Osteosarcoma cells K7 treated with IUA $(0,5,10 \mu \mathrm{mol} / \mathrm{L})$ after 48 hours. The obvious changes in cell-cycle distribution of K7 cells were characterized by a decrease of the S-phase and increase of the G1-phase cells in a dose-dependentmanner $(\mathrm{P}<0.05)$.

Fig. 5. IUA inhibits growth and induces apoptosis in osteosarcoma cells via the inhibition of JNK signaling pathway. Western-blot analysis was performed after treatment with IUA at 5 $\mu \mathrm{mol} / \mathrm{L}$ and $10 \mu \mathrm{mol} / \mathrm{L}$ for 12 hours. The levels of p65, p-p38, and p-ERK kinase, as well as ERK and p38 kinase, did not change (Fig. 5A). The levels of $p$-JNK kinase decreased significantly after the treatment with IUA as well as its down downstream protein, c-jun kinase, but the total JNK and c-jun changed inconspicuously (Fig. 5B). The same change in the JNK signaling pathway occurred in human osteosarcoma cell lines HOS (Fig. 5C) and Saos2 (Fig. 5D). K7 cells were treated with IUA (5 $\mu \mathrm{mol} / \mathrm{L})$, with JNK-selective inhibitor SP600125 (100 $\mu \mathrm{mol} / \mathrm{L})$, or with IUA ( $5 \mu \mathrm{mol} / \mathrm{L})$ and SP600125 (100 $\mu \mathrm{mol} / \mathrm{L})$ for $48 \mathrm{~h}$. Then cell viability was determined by MTT analysis (Fig. 5E). Treatment with IUA at $5 \mu \mathrm{mol} / \mathrm{L}$ and $10 \mu \mathrm{mol} / \mathrm{L}$ resulted in a marked increase of cleaved caspase- 3 protein in $\mathrm{K} 7$ cells (Fig. 5F).

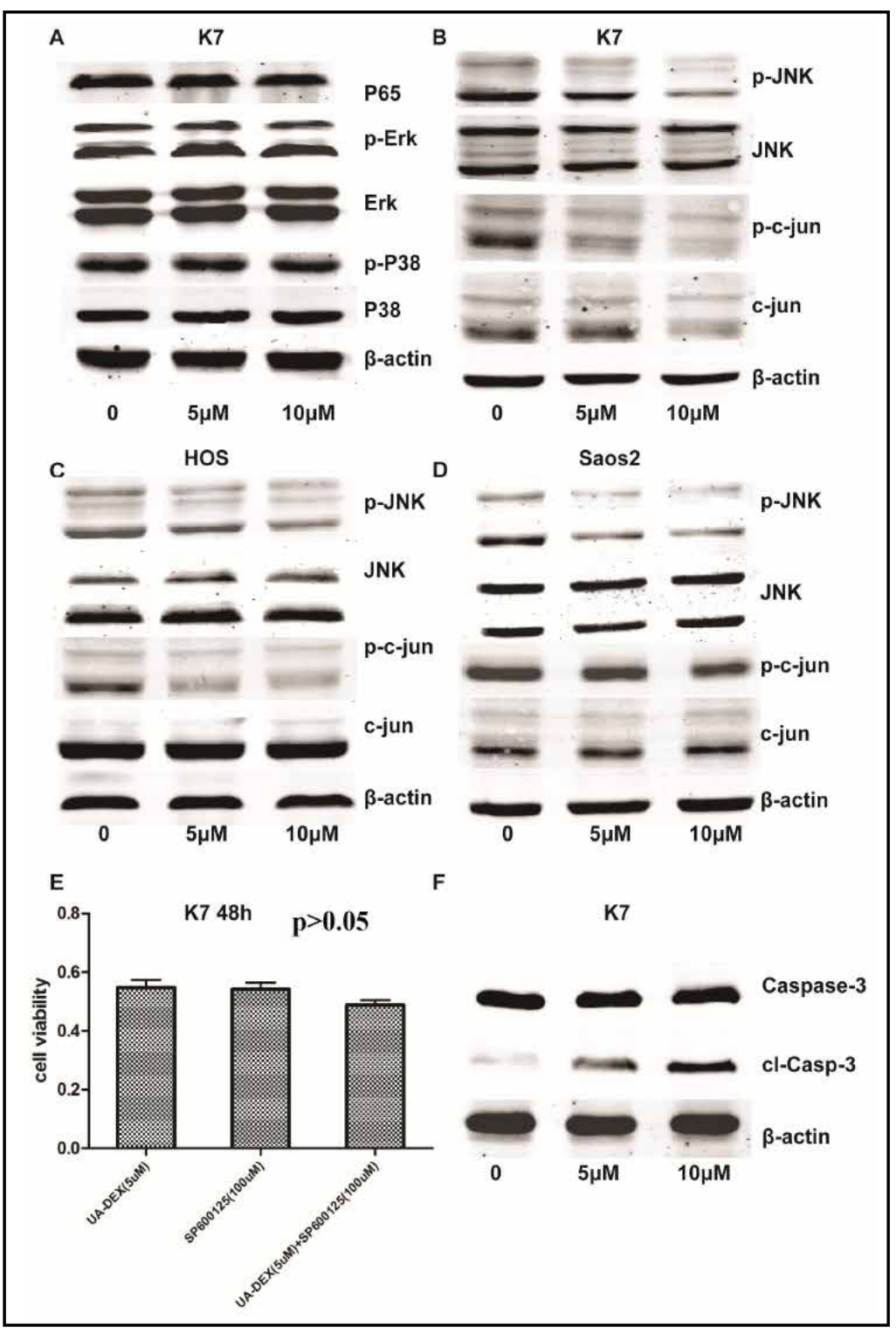

phase was increased, while the ratio of G2 phase just changed slightly (Fig. 4). Cells that were treated with $5 \mu \mathrm{mol} / \mathrm{Land} 10 \mu \mathrm{mol} / \mathrm{LIUA}$ for $48 \mathrm{~h}$ were composed of $57.85 \%$ and $58.62 \% \mathrm{G} 1$ - 
Fig. 6. Tumor growth was significantly inhibited by IUA in vivo. Tumor leg weight was significantly decreased post-IUA compared with the control group $(P=0.0027)$.

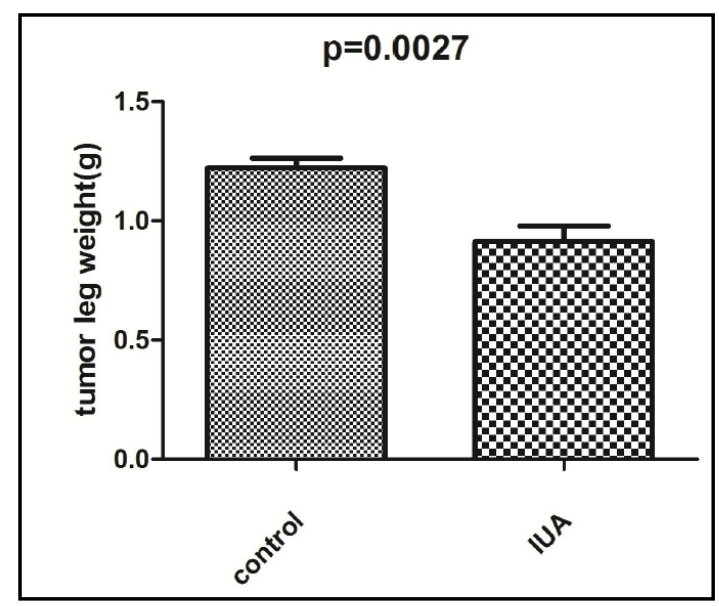

phase cells. When compared with untreated control cells, which had 38.79\% G1-phase cells $(P<0.05)$, these results suggested that IUA could suppress cell proliferation associated with cell-cycle arrest in the G1 phase.

IUA inhibits proliferation and induces apoptosis of osteosarcoma cells via the inhibition of JNK pathway

To elucidate the molecular mechanism by which IUA inhibits proliferation and induces apoptosis of osteosarcoma cells, we performed western-blot analysis after treatment with IUA at $5 \mu \mathrm{mol} /$ Land $10 \mu \mathrm{mol} /$ Lfor 12 hours to study the signaling pathways' change. The results showed that in osteosarcoma K7 cells, the levels of p-JNK kinase decreased significantly after the treatment with IUA, while the levels of p65, p-p38, and p-ERK kinase, as well as total JNK, ERK, and P38 did not change. In addition, the phosphorylation of JNK was negatively correlated with IUA concentration (Fig. 5A). In order to confirm our finding, we examined the JNK pathway's main downstream protein, $c$-jun, and we found that $\mathrm{p}$-c-jun was decreased, while total c-jun level was very slightly decreased. (Fig. 5B). We also detected similar changes in JNK pathway in HOS and Saos-2 cell lines (Fig. 5C, Fig. 5D). Interestingly, the total c-jun was not decreased in HOS and Saos-2. Moreover, the decrease in p-c-jun levels varied in cell lines and appeared to be modest in the Saos-2. We further examined whether IUA activates the caspase-dependent apoptotic pathway in K7 cells. The effects of IUA on expression of the cleaved proteins of three key apoptosis-related proteins (PARP, caspase-3, and caspase-9) were detected by western-blot analysis at 12 hours after treatment. As shown in Fig. 5F, treatment with IUA at $5 \mu \mathrm{mol} / \mathrm{L}$ and $10 \mu \mathrm{mol} / \mathrm{L}$ resulted in a marked increase of the cleaved caspase- 3 protein, but levels of cleaved PARP and cleaved caspase- 9 did not change (data not shown).

To further confirm the involvement of the JNK signaling pathways in the IUA-mediated apoptosis and inhibition of cell proliferation, we next analyzed the effects of the JNKselective inhibitor on IUA-mediated proliferation inhibition in K7 cells. Pretreatment of cells with JNK inhibitor SP600125 $(100 \mu \mathrm{mol} / \mathrm{L})$ or IUA $(5 \mu \mathrm{mol} / \mathrm{L})$ inhibited cell proliferation, however combination of IUA with SP600125 did not show increase in the inhibition rate of cell proliferation (Fig. 5E). This data suggested that the overlap of mechanism between two compound which supported the regulation of JNK pathway by IUA. However, IUA intriguingly is a more potent JNK inhibitor that with much lower IC50 compared to SP600125. These data indicated that IUA inhibits proliferation and induces apoptosis in osteosarcoma cells via the down-regulation of the JNK signaling pathway.

Osteosarcoma growth was inhibited by IUA in vivo

To examine the antitumor activity of IUA in vivo, we treated OS-bearing mice with IUA. The results showed that tumor weight was significantly decreased by IUA treatment compared to the control group $(P=0.0027)$ (Fig. 6). Water intake and gain in body weights 
did not differ significantly among the control and IUA-fed groups during the experimental period (data not shown). In addition, no mouse died during treatment with either compound or from the control group until the end of the experiments (data not shown). These results indicate that IUA had an anti-osteosarcoma effect in vivo.

\section{Discussion}

Ursolic acid as a natural pentacyclic triterpenoid carboxylic acid exists widely in medical herbs and edible plants and has been shown to exhibit low systemic toxicity along with a wide range of biological activities, including prevention and protection against cancers and inducing the apoptosis of cancer cells [22]. However, the precise molecular mechanisms and signaling pathways by which UA induces apoptosis and proliferation inhibition remain unclear. The main adverse effects of UA are impaired male fertility, sperm motility inhibition, and DNA damage $[23,24]$.

Apoptosis is a form of cell death coordinated by a network of genes and is a key target in the development of new anti-cancer therapies. Apoptosis can be activated through at least two signaling pathways: caspase-dependent and caspase-independent [25]. Several studies have suggested that JNK cascades have a critical role in regulating cytotoxic drug-induced apoptosis in osteosarcoma. JNK is known to be involved in controlling diverse cellular functions, such as cell proliferation, differentiation, and apoptosis based on phosphorylation $[26,27]$. Many cancers, including retinoblastoma, melanoma, breast and ovarian cancers, exhibit elevated JNK activity. The activation of JNK in osteosarcoma cells is also higher compared to osteoblastic cells [28]. In some instances, the role of JNK in apoptosis is further complicated. The role of the JNK pathway in apoptosis is both cell type- and stimulusdependent. Furthermore, individual JNK isoforms can play different roles in regulation of the apoptotic process, and different components of the JNK cascade can have opposing roles in apoptosis, even in the same cell type in response to identical death stimuli [20].

In this study, we synthesized a new UA-derivative with the goal of strengthening the biological activity of UA. We found that IUA could induce apoptosis and inhibit the proliferation of osteosarcoma cells in vitro and in vivo. To elucidate the mechanisms of our synthetic UA derivative's anticancer actions, we first investigated its pro-apoptotic properties. Utilization of propidium iodide (PI) and fluorescein isothiocyanate (FITC)conjugated Annexin V (Annexin V-FITC) is a standard procedure to monitor the progression of apoptosis [29]. Annexin V-FITC/PI double staining showed that IUA induced apoptosis in a dose-dependent manner. We also found that osteosarcoma cells treated with IUA had a decrease of the S-phase and increase of the G1-phase cells , which led us to hypothesize that IUA exerts its anti-tumor effect through arresting cells in the G1 phase.

Members of the MAPK family and Akt are important regulators of stress responses, including the induction of apoptosis. Several studies have suggested that Akt, p38, JNK, and ERK1/2 cascades have critical roles in the induction of apoptosis [30, 31]. Therefore, to elucidate the mechanisms underlying IUA-induced apoptosis, the levels of Akt, p-Akt, p38, p-p38, JNK, p-JNK, ERK1/2, and p-ERK1/2 were analyzed by Western blotting in osteosarcoma cells. The p-JNK levels were suppressed by IUA. The JNK pathway downstream protein c-jun then was analyzed, and we found that p-c-jun was also suppressed. The p-c-jun surpress degree were a little different in K7, HOS and Saos-2, probably due to the total p-cjun protein content and sensibility to this drug had some variations in different cells. This result was consistent with suppression of JNK. To further confirm the involvement of the JNK signaling pathway in IUA-mediated apoptosis and inhibition of cell proliferation, we next analyzed the effects of JNK-selective inhibitor on IUA-mediated proliferation inhibition in K7 cells. Pretreatment of cells with JNK inhibitor SP600125 $(100 \mu \mathrm{mol} / \mathrm{L})$ or IUA (5 $\mu \mathrm{mol} / \mathrm{L})$ inhibited cell proliferation at about $50 \%$, and a combination of IUA ( $5 \mu \mathrm{mol} / \mathrm{L})$ with SP600125 $(100 \mu \mathrm{mol} / \mathrm{L})$ slightly increased the inhibition of cell proliferation. However, the addition of IUA did not significantly change proliferation inhibition in the K7 cells pretreated 
with JNK inhibitor, confirming the role of IUA in regulating JNK signaling. These results suggest that IUA is a selective JNK inhibitor. Apoptotic cell death is a highly regulated process that is characterized by stereotypical morphological changes of the cellular architecture. Activated caspases 3 has been identified as one of the key regulator enzymes that mediate these morphological apoptotic hallmarks [29]. An increase in cleaved caspase-3 protein was detected perhaps because the JNK-dependent apoptotic signaling pathway and caspasedependent apoptotic signaling pathway can interact with each other [32]. Specifically, the start-over of JNK-dependent apoptosis by IUA may also affect some caspase-dependent apoptotic signaling pathway.In summary, IUA inhibited the phosphorylation of JNK protein, resulting in an inactivation of the cell growth and apoptosis-related JNK signaling pathway. Inactivation of the JNK signaling pathway might through trigger mitochondrial depolarization and the release of cytochrome $\mathrm{c}$ to the cytosol to stimulate the activation of caspase-3 [33], thereby induced JNK-dependent and caspase-dependent apoptosis. In our in vivo study, we found that IUA $(20 \mathrm{mg} / \mathrm{kg} / \mathrm{d})$ obviously inhibited tumor growth during the 2-week treatment period. Therefore, we infer that IUA inhibits osteosarcoma growth and induces apoptosis via the down-regulation of the JNK signaling pathway. Our results revealed evidence of the biological mechanism of IUA on osteosarcoma cells.

\section{Conclusion}

To the best of our knowledge, the newly synthetic ursolic acid derivative IUA we used in this study is a new derivative of ursolic acid, and it is the first derivative reported to have anti-tumor activity when tested on osteosarcoma cells in vitro and in vivo. Although we found that IUA inhibits proliferation and induces apoptosis in osteosarcoma cells via the down-regulation of the JNK signaling pathway specifically, it remains to be seen if there are other intersecting pathways by which this compound exerts its anti-proliferative, apoptotic, cell cycle-modulating activities. Our findings suggest that our new synthetic, IUA, may be a promising agent for the prevention and treatment of human osteosarcoma.

\section{Acknowledgements}

This study was supported by National Natural Science Foundation of China (81202115, 21272114), the Key Project of Basic Research of Shanghai (11JC1410101), the Shanghai Pujiang Program (12PJ1407100), Innovative Frontier Technology Program of Shenkang (SHDC12013107) and the Excellent Young Talent Program of Shanghai Municipal Commision of Health and Family Planning(XYQ2013108).

\section{References}

1 Longhi A, Errani C, De Paolis M, Mercuri M, Bacci G: Primary bone osteosarcoma in the pediatric age: state of the art. Cancer Treat Rev 2006;32:423-436.

-2 Marina N, Gebhardt M, Teot L, Gorlick R: Biology and therapeutic advances for pediatric osteosarcoma. Oncologist 2004;9:422-441.

-3 Anninga JK, Gelderblom H, Fiocco M, Kroep JR, Taminiau AH, Hogendoorn PC, Egeler RM: Chemotherapeutic adjuvant treatment for osteosarcoma: where do we stand? Eur J Cancer 2011;47:24312445.

4 Kazakova OB, Giniyatullina GV, Yamansarov EY, Tolstikov GA: Betulin and ursolic acid synthetic derivatives as inhibitors of Papilloma virus. Bioorg Med Chem Lett 2010;20:4088-4090.

5 Cunha WR, de Matos GX, Souza MG, Tozatti MG, Andrade e Silva ML, Martins CH, da Silva R, Da Silva Filho AA: Evaluation of the antibacterial activity of the methylene chloride extract of Miconia ligustroides, isolated triterpene acids, and ursolic acid derivatives. Pharm Biol 2010;48:166-169.

6 Jin YR, Jin JL, Li CH, Piao XX, Jin NG: Ursolic acid enhances mouse liver regeneration after partial hepatectomy. Pharm Biol 2012;50:523-528. 
7 Liu W, Tan X, Shu L, Sun H, Song J, Jin P, Yu S, Sun M, Jia X: Ursolic acid inhibits cigarette smoke extractinduced human bronchial epithelial cell injury and prevents development of lung cancer. Molecules 2012;17:9104-9115.

8 Wang J, Liu L, Qiu H, Zhang X, Guo W, Chen W, Tian Y, Fu L, Shi D, Cheng J, Huang W, Deng W: Ursolic acid simultaneously targets multiple signaling pathways to suppress proliferation and induce apoptosis in colon cancer cells. PLoS One 2013;8:e63872.

-9eal AS, Wang R, Salvador JA, Jing Y: Synthesis of novel ursolic acid heterocyclic derivatives with improved abilities of antiproliferation and induction of p53, p21waf1 and NOXA in pancreatic cancer cells. Bioorg Med Chem 2012;20:5774-5786.

10 Seki E, Brenner DA, Karin M: A liver full of JNK: signaling in regulation of cell function and disease pathogenesis, and clinical approaches. Gastroenterology 2012;143:307-320.

$\checkmark 11$ Kyriakis JM, Avruch J: pp54 microtubule-associated protein 2 kinase. A novel serine/threonine protein kinase regulated by phosphorylation and stimulated by poly-L-lysine. J Biol Chem 1990;265:17355-17363.

12 Kyriakis JM, Brautigan DL, Ingebritsen TS, Avruch J: pp54 microtubule-associated protein-2 kinase requires both tyrosine and serine/threonine phosphorylation for activity. J Biol Chem 1991;266:10043-10046.

13 Shen HM, Liu ZG: JNK signaling pathway is a key modulator in cell death mediated by reactive oxygen and nitrogen species. Free Radic Biol Med 2006;40:928-939.

14 Eilers A, Whitfield J, Shah B, Spadoni C, Desmond H, Ham J: Direct inhibition of c-Jun N-terminal kinase in sympathetic neurones prevents c-jun promoter activation and NGF withdrawal-induced death. J Neurochem 2001;76:1439-1454.

-15 Bonny C, Oberson A, Negri S, Sauser C, Schorderet DF: Cell-permeable peptide inhibitors of JNK: novel blockers of beta-cell death. Diabetes 2001;50:77-82.

16 Graczyk PP: JNK inhibitors as anti-inflammatory and neuroprotective agents. Future Med Chem 2013;5:539-551.

17 Hreniuk D, Garay M, Gaarde W, Monia BP, McKay RA, Cioffi CL: Inhibition of c-Jun N-terminal kinase 1, but not c-Jun N-terminal kinase 2, suppresses apoptosis induced by ischemia/reoxygenation in rat cardiac myocytes. Mol Pharmacol 2001;59:867-874.

18 Potapova O, Gorospe M, Dougherty RH, Dean NM, Gaarde WA, Holbrook NJ: Inhibition of c-Jun N-terminal kinase 2 expression suppresses growth and induces apoptosis of human tumor cells in a p53-dependent manner. Mol Cell Biol 2000;20:1713-1722.

19 Andreka P, Zang J, Dougherty C, Slepak TI, Webster KA, Bishopric NH: Cytoprotection by Jun kinase during nitric oxide-induced cardiac myocyte apoptosis. Circ Res 2001;88:305-312.

20 Sabapathy K: Role of the JNK pathway in human diseases. Prog Mol Biol Transl Sci 2012;106:145-169.

21 Fu HJ, Zhou YR, Bao BH, Jia MX, Zhao Y, Zhang L, Li JX, He HL, Zhou XM: Tryptophan hydroxylase 1 (tph-1)targeted bone anabolic agents for osteoporosis. J Med Chem 2014;57:4692-4709.

-22 Zheng QY, Li PP, Jin FS, Yao C, Zhang GH, Zang T, Ai X: Ursolic acid induces ER stress response to activate ASK1-JNK signaling and induce apoptosis in human bladder cancer T24 cells. Cell Signal 2013;25:206-213. Lin A, Dibling B: The true face of JNK activation in apoptosis. Aging Cell 2002;1:112-116.

$\$ 24$ Chattopadhyay D, Dungdung SR, Mandal AB, Majumder GC: A potent sperm motility-inhibiting activity of bioflavonoids from an ethnomedicine of Onge, Alstonia macrophylla Wall ex A. DC, leaf extract. Contraception 2005;71:372-378. Spencer SL, Sorger PK: Measuring and modeling apoptosis in single cells. Cell 2011;144:926-939. Noh K, Kim KO, Patel NR, Staples JR, Minematsu H, Nair K, Lee FY: Targeting inflammatory kinase as an adjuvant treatment for osteosarcomas. J Bone Joint Surg Am 2011;93:723-732.

27 Chen YC, Chang CN, Hsu HC, Chiou SJ, Lee LT, Hseu TH: Sennoside B inhibits PDGF receptor signaling and cell proliferation induced by PDGF-BB in human osteosarcoma cells. Life Sci 2009;84:915-922.

28 Li GD, Cai ZD, Zhang YQ Gong HY, Tang H, Zhang QL: [Gene profiling of MAPK pathway in human osteosarcoma]. Zhonghua Zhong Liu Za Zhi 2009;31:340-345.

29 Brauchle E, Thude S, Brucker SY, Schenke-Layland K: Cell death stages in single apoptotic and necrotic cells monitored by Raman microspectroscopy. Sci Rep 2014;4:4698.

30 Liang CZ, Zhang X, Li H, Tao YQ, Tao LJ, Yang ZR, Zhou XP, Shi ZL, Tao HM: Gallic acid induces the apoptosis of human osteosarcoma cells in vitro and in vivo via the regulation of mitogen-activated protein kinase pathways. Cancer Biother Radiopharm 2012;27:701-710.

-31 Ding D, Wei S, Song Y, Li L, Du G, Zhan H, Cao Y: Osthole Exhibits Anti-Cancer Property in Rat Glioma Cells Through Inhibiting PI3K/Akt and MAPK Signaling Pathways. Cell Physiol Biochem 2013;32:1751-1760.

-32 Dhanasekaran DN, Reddy EP: JNK signaling in apoptosis. Oncogene 2008;27:6245-6251.

-33 Sun XM, MacFarlane M, Zhuang J, Wolf BB, Green DR, Cohen GM: Distinct caspase cascades are initiated in receptor-mediated and chemical-induced apoptosis. J Biol Chem 1999;274:5053-5060. 